\title{
STUDI METODE-METODE EKSTRAKSI PEWARNA MAKANAN ALAMI ANNATTO DARI BIJI KESUMBA (Bixa orellana)
}

\author{
Johnner Parningotan Sitompul ${ }^{*}$, Martha Febi Situmorang, dan Tatang Hernas \\ Soerawidjaja
}

\author{
Program Studi Teknik Kimia, Fakultas Teknologi Industri, Institut Teknologi Bandung \\ Jl. Ganesha 10, Bandung 40123, Indonesia \\ ${ }^{*}$ Penulis korespodensi: sitompul@che.itb.ac.id
}

\begin{abstract}
A STUDY ON THE EXTRACTION METHODS FOR NATURAL FOOD COLORANT ANNATTO FROM KESUMBA (Bixa orellana). Annatto is natural food colorant extracted from Bixa orellana seeds. The main constituent of annatto is bixin, a carotenoid having carboxylic acid groups at both ends of its molecular chain and one of these is methyl-esterified. The carboxylic acid groups of bixin and norbixin cause the molecule to dissolve in aqueous bases. The methyl ester structure causes the molecule dissolving in oil and other organic solvents. The double bond conjugated chain causes bixin dissolved in most organic solvents. These characteristics are mainly bases for extraction solvent selection. The objectives of this research are to evaluate the performance of ethyl acetate and acetone as solvents for annatto extraction with different method of extraction and to obtain a procedure for preparing general purpose annatto extract having the highest possible of bixin yield. Two methods of extraction are carried out using Soxhlet method (at solvent boiling temperature) and ultrasonic bath extraction at room temperature. The selected solvents are ethyl acetate and acetone that have medium polarity index and low boiling point. The bixin quality is examined by measuring pigment content with spectrophotometer at certain wavelength. Two types of seeds from different places in Indonesia will be the investigated as sources of annatto. Experimental results for extraction with Soxhlet method shows that yield of bixin (upon seed) from ultrasonic bath extraction is higher that is $0.584 \%$ (w), compared to Soxhlet extraction $0.443 \%(w)$. For ultrasonic bath extraction, yield of bixin (upon seed) with ethyl acetate as solvent is $0.602 \%$, much higher compared to that from acetone 0.565\%. Extraction with Soxhlet method gives different results. Yield of bixin (upon seed) with acetone as solvent is higher which is $0.460 \%$, compared to ethyl acetate which is $0.427 \%$. Seeds from Bandung (West Java) and Duri (Riau) do not give significant difference of bixin yield from two methods of extraction.
\end{abstract}

Keywords: annatto; bixin; extraction; organic solvent; soxhlet; ultrasonic bath

\begin{abstract}
Abstrak
Annatto merupakan pewarna alami makanan yang didapatkan melalui ekstraksi dari biji pohon kasumba (Bixa orellana) dengan komponen pewarna utamanya adalah bixin. Keberadaan ikatan rangkap terkonjugasi menyebabkan bixin dan norbixin larut dalam sebagian besar pelarut organik. Ciri struktur kimia dari bixin ini yang menjadi dasar dalam pemilihan pelarut untuk ekstraksi pewarna annatto. Tujuan makalah ini adalah studi metode-metode ekstraksi terhadap perolehan bixin, metode Soxhlet pada temperatur didih pelarut dan metoda ultrasonic bath pada temperatur kamar, dengan dua tempat sumber biji kasumba, Bandung dan Duri. Pelarut yang digunakan adalah etil asetat dan aseton. Pengujian dilakukan dengan mengukur kadar pigmen yang dihasilkan menggunakan spektrofotometri pada panjang gelombang tertentu. Dari penelitian ini, didapatkan data yield (perolehan bixin) dari berbagai variasi percobaan. Perolehan bixin (terhadap biji) yang didapat dari ekstraksi ultrasonic bath lebih tinggi yaitu rata-rata sebesar 0,584\%, dibanding dengan metode soxhlet yang rata-rata sebesar 0,443\%. Ekstraksi menggunakan metode ekstraksi ultrasonic bath, dan menggunakan pelarut etil asetat lebih tinggi yaitu rata-rata 0,602\% daripada menggunakan aseton yang rata-rata 0,565\%. Sedangkan dengan metode soxhlet menunjukkan perolehan bixin berbeda, dengan pelarut aseton 0,460\%, sedangkan untuk pelarut etil asetat adalah 0,427\%. Biji yang berasal dari 2 tempat berbeda, ketika diekstraksi dengan dua metode tersebut tidak memberikan perbedaaan hasil bixin yang signifikan
\end{abstract}

Kata kunci: annatto; bixin; ekstraksi; solven organik; soxhlet; ultrasonic bath 


\section{PENDAHULUAN}

Penampilan makanan, termasuk warnanya, sangat mempengaruhi selera konsumen. Penambahan zat pewarna pada makanan bertujuan untuk membuat makanan lebih menarik. Zat pewarna sendiri secara luas digunakan di seluruh dunia, baik pewarna sintetik atau pewarna alami. Namun, bahaya yang dapat ditimbulkan oleh pewarna sintetik terhadap tubuh menyebabkan pemakaiannya di dalam makanan diawasi ketat oleh suatu institusi dalam suatu negara. Oleh karena itu, sekarang konsumen cenderung memakai zat warna alami. Salah satu zat alami tersebut adalah pewarna annatto, yang diperoleh melalui ekstraksi dari biji pohon tropik Bixa orellana. Di Indonesia pohon ini banyak ditemukan dan namanya dikenal antara lain adalah kasumba. Nama lainnya (Heyne, 1950) didasarkan atas etnik di Indonesia seperti galuga atau pacar galuga (Jawa), galinggem (Sunda), Kasumbo (Nias), sumba atau tuwa (Minahasa), Taluka (Ambon). Pohon ini juga dikenal dalam bahasa asing, dengan nama Rocouyer (Perancis), Orleanbaum (Jerman), annatto tree or achiote (Inggris), achiote (Spanyol), Oelinggem, galuga (Melayu Malaysia) dan urucum (Portugis). Selanjutnya dalam makalah ini, pohon atau biji Bixa Orellana disebut pohon atau biji kasumba.

Makanan seperti keju, ikan, daging, es krim, mentega, margarin memakai zat warna annatto sebagai pewarnanya. Seiring dengan peningkatan konsumsi makanan tersebut, maka kebutuhan akan zat warna annatto juga akan ikut meningkat. Menurut data Smith (2006), konsumsi biji annatto terbesar adalah di Amerika Utara (3000 ton), Eropa (2500 ton), dan Jepang (1500 ton). Mereka adalah pengimpor annatto terbesar di dunia. Pada tahun 2006, total 7600 ton metrik biji kasumba diimpor dari negara produsen di seluruh dunia. Produsen besar yang menyediakan biji kasumba berasal dari negara Brazil (5000 ton metrik), Peru, Ekuador, Kolombia, Bolivia (total 3000 ton metrik), Kenya dan Tanzania (2500 ton metrik).

Di Indonesia, manfaat pohon kasumba relatif masih terabaikan (underutilized). Padahal Indonesia berpotensi menjadi produsen biji kasumba maupun pewarna annatto (Hyman dkk., 1990). Potensi yang besar ini dapat dilihat dari tersebarnya pohon kasumba di seluruh Indonesia. Untuk meningkatkan nilai tambah dari biji kasumba, maka biji harus diproses sehingga menghasilkan ekstrak annatto yang memenuhi standar negara pengimpor seperti Eropa dan Amerika Serikat (FAO/WHO, 2006). Dengan membuat ekstrak annatto yang memenuhi standar dunia, diharapkan Indonesia dapat memproduksi pewarna alami pangan ini untuk kebutuhan dalam negeri maupun ekspor.

\section{Pigmen Annatto}

Komposisi biji kasumba terdiri dari lapisan terluar (aril) dimana pigmen (zat warna) berada, kulit biji dan biji terdalam (kernel). Zat warna utama dari biji kasumba adalah karotenoid bixin dan norbixin.
Perbedaan kedua komponen ini dapat diperiksa secara stereokimia, kelarutan, sifat kromatografi dan kestabilannya. Umumnya karotenoid memiliki rumus molekul $\mathrm{C}_{40} \mathrm{H}_{56}$, yaitu hidrokarbon yang terbentuk dari delapan unit isoprena $\left(\mathrm{C}_{5} \mathrm{H}_{8}\right)$, sehingga ia merupakan poliena. Isoprena bergabung pada posisi kepala-ekor membentuk struktur alifatik karotenoid, kecuali pada bagian pusat, 2 isoprena bergabung pada posisi ekorekor, menyebabkan bentuk molekul simetrik (Rigaudy dan Klesney, 1979; Ribeiro dkk., 2004)). Pada kedua ujung molekul, terdapat gugus $\mathrm{R}$ yang bisa berupa rantai terbuka atau cincin.

Tabel 1. Komposisi biji kasumba (Ribeiro dkk., 2004)

\begin{tabular}{ll}
\hline \multicolumn{1}{c}{ Lapisan } & \multicolumn{1}{c}{ Kandungan } \\
\hline Biji terdalam & Minyak, substansi lilin, abu \\
(kernel) & mineral, dan komponen alkaloid \\
Kulit biji & Selulosa dan tannin \\
Lapisan terluar (aril) & Pigmen, air, dan sedikit minyak \\
\hline
\end{tabular}

Ciri khas yang penting dari struktrur molekul karotenoid adalah ikatan rangkap terkonjugasi yang panjang dan terpusat (Mercadante dkk., 1990). Ikatan rangkap ini merupakan molekul pemberi warna (kromofor) yang menyerap cahaya. Oleh karena kromofor inilah, karotenoid mempunyai warna yang atraktif dan memberikan spektrum serapan cahaya tampak yang akan menjadi basis untuk identifikasi dan kuantifikasi molekul karotenoid (Amaya dan Kimura, 2004). Oleh karena itu, baik norbixin dan bixin disebut diapokarotenoid, yaitu molekul turunan karotenoid dengan rangka karbon yang telah diperpendek karena penyingkiran fragmen pada kedua ujung molekul karotenoid. Molekul bixin sendiri adalah norbixin yang diesterifikasi pada salah satu gugus karboksilat di ujungnya yang disubstitusi dengan radikal metil (Hendry, 1992).

\section{Proses Pembuatan Pewarna Annatto}

Biji kasumba dapat diproses dengan dua cara dasar. Proses pertama adalah pelarutan biji kasumba di dalam larutan akuatik yang bersifat basa. Proses ini didasarkan pada sifat gugus asam karboksilat dari bixin dan norbixin yang menyebabkan molekul dapat larut dalam air dengan penambahan basa. Proses lainnya adalah mengekstraksi pigmen menggunakan satu atau lebih pelarut organik. Teknik pemrosesan ini berdasarkan struktur molekul dari bixin dalam pigmen annatto. Bentuk ester pada bixin menyebabkan molekul dapat larut dalam minyak, sedangkan keberadaan ikatan rangkap terkonjugasi menyebabkan bixin dan norbixin larut dalam sebagian besar pelarut organik (MacDougall, 2002; Scotter, 2009).

\section{Pemilihan Pelarut Organik}

Secara umum, ada 3 pelarut untuk produksi pewarna annatto yang ada di literatur (Hendry, 1992), yaitu ekstraksi dengan pelarut organik tak mudah menguap (minyak-lemak), ekstraksi dengan pelarut mudah menguap dan ekstraksi dengan larutan akuatik. Literatur menunjukkan bahwa pelarut organik mudah 
menguap yang berindex kepolaran medium menghasilkan tingkat perolehan bixin paling tinggi. Namun ada kendala pada pemrosesan pada suhu tinggi dikarenakan bixin akan rusak apabila suhu proses ekstraksi diatas $80^{\circ} \mathrm{C}$. Jadi, harus dipilih pelarut yang memiliki titik didih tidak terlalu tinggi dan memiliki nilai indeks polaritas tertentu (Cardarelli dkk., 2008).

Menurut Cardarelli dkk. (2008), efisiensi ekstraksi kadar bixin dari suatu pelarut organik yang tepat akan menyebabkan perolehan kadar bixin yang paling tinggi. Lebih jauh, efisiensi ekstraksi dari bixin sangat berhubungan dengan polaritas pelarut. Bixin yang berstruktur rantai karbon $\mathrm{C}_{25}$ dengan gugus asam dan ester metil bersifat polar-tak polar dan menunjukkan sifat afinitas yang tinggi untuk pelarut berkepolaran medium. Karena ini, pelarut disarankan berindex polaritas sekitar 3,9-5,5. Pelarut yang memiliki kepolaran medium, memenuhi mutu pangan dan bertitik didih tidak terlalu tinggi dan pelarut yang masuk pada kriteria ini pelarut aseton, etil asetat dan etanol. Menurut Cardarelli dkk., etil asetat memiliki efisiensi kelarutan paling tinggi dibanding metanol dan etanol. Namun titik didih etil asetat masih sedikit lebih tinggi dibanding dengan aseton. Oleh karena itu, pengujian pemilihan etil asetat dan aseton sebagai pelarut dalam ekstraksi annatto, layak untuk dilakukan.

\section{METODE PENELITIAN}

\section{Bahan dan Metodologi Percobaan}

Percobaan yang dilakukan terdiri dari ekstraksi pewarna annatto dari biji kasumba, pengukuran data kandungan bixin yang dihasilkan produk dan pembuatan Bixin yang akan digunakan menjadi standar. Ekstraksi pewarna annatto dilakukan menggunakan dua jenis pelarut organik etil asetat dan aseton. Biji kasumba sebanyak dalam jumlah tertentu diekstrak dengan dua metode ekstraksi ultrasonic bath, pada suhu kamar dan metode ekstraksi Soxhlet pada suhu titik didihnya. Masing-masing percobaan dilakukan duplo. Perolehan kandungan bixin yang paling tinggi kemudian di lakukan kembali untuk mendapatkan hasil yang lebih banyak. Pengukuran kandungan bixin dalam pewarna annatto dilakukan dengan metode spektrofotometri mengunakan $\mathrm{NaOH}$ 0,1 N pada panjang gelombang $470 \mathrm{~nm}$. Sedangkan pembuatan bixin standar dilakukan dengan mengekstraksi biji annatto hingga mendapatkan padatan pigmen terluar dari biji.

\section{Peralatan}

Seperti dijelaskan di atas, ada dua metode ekstraksi yang akan diterapkan. Untuk peralatan metode ekstraksi Soxhlet volume $500 \mathrm{ml}$ ditunjukkan pada Gambar 1 dan Soxhlet tersebut terbuat dari gelas dengan ketebalan bahan sebesar $1 \mathrm{~mm}$. Untuk metode ekstraksi dengan ultrasonic bath, gelas kimia dengan volume tertentu di masukkan dalam ultrasonic bath dan prosedur percobaan diberikan di bawah ini.

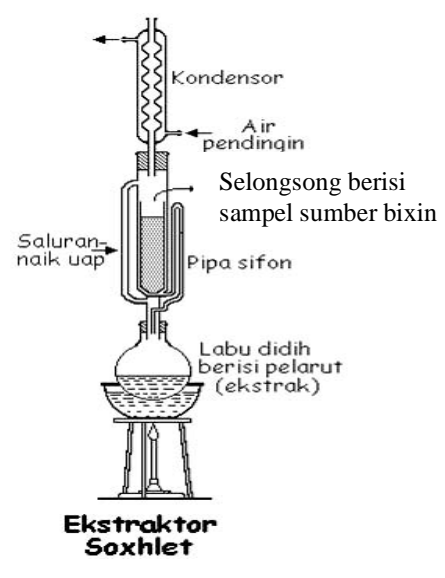

Gambar 1. Skema metode ekstraksi soxhlet

\section{Prosedur Percobaan \\ Pembuatan standar bixin}

Larutan standar bixin diperoleh secara eksperimen dengan prosedur yang dikembangkan dari literature yang ada (Massarani, 1992; Smith, 2006). Biji Bixa orellana direndam dalam air sehingga biji sedikit mengembang dan kemudian diaduk selama beberapa jam. Setelah dilakukan penyaringan diperoleh air lumpur yang mengandung bixin tersuspensi dan dituangkan ke dalam percolator besar dan diamkan semalaman. Cairan akan membentuk 2 lapisan, lapisan atas berwarna merah pucat, lapisan bawah berwarna merah tua. Pisahkan cairan atas dengan bawah dengan cara menghisap cairan atas. Sentrifugasi lapisan bawah dan sentrifugat yang terbentuk dihancurkan. Kemudian sentrifugat dikeringkan secara vakum dengan $\mathrm{CaCl}_{2}$. Sentrifugat kemudian digiling dan kemudian dari sentrifugat diperoleh bixin. Kemudian bagian material yang kering, dicampur alkohol p.a. $96 \%$ pada temperatur tertentu. Kontakkan gas ammonia ke dalam larutan sampai perubahan warna tidak terjadi lagi dan larutan tidak mengandung ammonia. Dalam keadaan hangat, larutan disaring. Residu yang tertinggal dicampur lagi dengan etanol p.a. $96 \%$ gas amoniak dilewatkan pada campuran ini. Sentrifugat dan filtrat yang ada dicampur dan dinginkan sehingga membentuk endapan ammonium bixat. Terhadap senyawa ini kemudian ditambahkan sejumlah asam asetat glacial, dan diaduk merata dan dibiarkan terjadi pengendapan. Resin berwarna merah tua yang terbentuk dipisahkan dari cairan induk dan dicampur dengan asam asetat dan sambil diaduk, bixin akan terpisah dan disaring. Setelah itu bixin dikeringkan dalam keadaan vakum dan setelah itu larutan dikristalisasi sehingga diperoleh bixin standar.

Metoda ekstraksi pewarna Annatto dengan soxhlet Sejumlah biji kasumba dimasukkan ke dalam selongsong/ timbel Soxhlet dan menutup atas dengan kapas untuk mencegah kontaminasi bahan. Pelarut organik dimasukkan ke dalam labu bundar. Sampel biji kasumba diekstrak pada temperatur didih pelarut 
untuk 20-30 siklus ekstraksi. Setelah biji terkelupas semua maka pelarut dikeluarkan dari dalam wadah labu didih dan pigmen dipisahkan dari pengotor dan dihitung yield/ perolehan (terhadap biji).

\section{Metoda ekstraksi pewarna Annatto dengan ultrasonic bath}

Sejumlah biji kasumba dicampurkan dengan organik dengan menggunakan gelas kimia. Biji diletakkan pada gelas kimia dan tuangkan pelarut organik ke dalamnya dan sampel diekstrak dalam ultrasonik bath pada pada temperatur kamar/ ruang. Kemudian pigmen didekantasi dari pelarut dan hasil ekstrak ditampung pada wadah baru. Ulangi ekstrak sampai 4 kali menggunakan pelarut yang sama dan tampung hasil ekstrak pada wadah yang baru. Ekstrak yang terkumpul dianalisa kadar bixin-nya dengan spektrofotometer.

\section{HASIL DAN PEMBAHASAN}

\section{Perolehan Bixin dari Variasi Metode}

Metode ekstraksi dilakukan dalam dua variasi, yaitu mengekstraksi pada suhu kamar dengan ultrasonic bath (yang dilakukan oleh Cardarelli dkk, 2008) dan ekstraksi pada titik didih dengan metode Soxhlet. Ekstraksi ultrasonic bath dilakukan pada suhu kamar dengan masing-masing pelarut setiap kali ekstraksi sebanyak $40 \mathrm{ml}$. Metode Soxhlet dilakukan selama waktu terntentu dengan memastikan seluruh pigmen dapat terlepas dari biji. Berdasarkan hasil percobaan yang diperlihatkan pada Gambar 2, perolehan bixin (terhadap biji) yang didapat dari ekstraksi suhu kamar Ultrasonic lebih tinggi, rata-rata sebesar $0,584 \%$, dibanding jika ekstraksi dilakukan dengan metode Soxhlet yang menghasilkan perolehan bixin terhadap biji rata-rata sebesar $0,443 \%$.

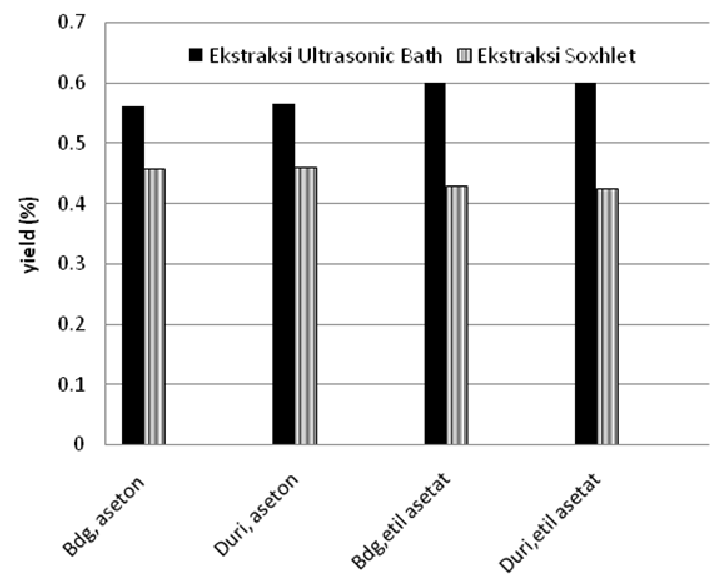

Gambar 2. Perbandingan yield (perolehan) bixin terhadap biji dari variasi metode ekstraksi

Hasil tersebut sesuai dengan hasil penelitian yang dilakukan oleh Massarani dkk. (1992) dan Shuahama dkk. (2003). Konsentrasi bixin akan menurun apabila terpapar suhu proses yang tinggi. Selama berlangsungnya ekstraksi, pelarut dan hasil ekstrak bixin yang berada dalam labu bundar terpapar suhu tinggi akibat pemanasan. Suhu labu bundar dapat mencapai $80^{\circ} \mathrm{C}$. Pemanasan bixin yang terus menerus akan menyebabkan bixin terdegradasi dan menghasilkan pigmen warna kuning. Hal ini menyebabkan kandungan bixin menurun. Dari Gambar 2 menampilkan perbandingan hasil percobaan yield (perolehan) bixin dengan metode ekstraksi ultrasonic bath yang lebih tinggi dibanding dengan metode ekstraksi Soxhlet.

\section{Perolehan Bixin dari Metode Ekstraksi dan Variasi Pelarut}

Pelarut yang digunakan dalam penelitian adalah etil asetat dan aseton. Etil asetat dan aseton yang digunakan keduanya adalah pelarut teknis. Etil asetat memiliki suhu titik didih $77^{\circ} \mathrm{C}$ dan indeks polaritas pelarut 4,4 dan aseton memiliki titik didih $56^{\circ} \mathrm{C}$ dengan indeks polaritas pelarut 5,1. Gambar 3 memperlihatkan yield (perolehan) bixin dengan memvariasikan pelarut pada metode ekstraksi ultrasonic bath. Konsentrasi bixin diperoleh dari kurva kalibrasi bixin standard dan yield dihitung dengan membandingkan bixin yang diperoleh terhadap bixin awal dalam biji.

Dari hasil percobaan, untuk ekstraksi menggunakan metode ekstraksi ultrasonic bath, perolehan bixin terhadap biji menggunakan pelarut etil asetat lebih tinggi yaitu rata-rata sebesar $0,602 \%$ daripada perolehan bixin menggunakan aseton yang rata-rata sebesar $0,565 \%$. Hal ini dikarenakan nilai indeks polaritas etil asetat 4,4 dan indeks polaritas aseton pada 5,1. Keduanya berada rentang indeks polaritas medium, dimana indeks polaritas medium memberikan hasil ekstraksi bixin yang lebih banyak akibat sifat polaritas dari ikatan rangkap yang dimiliki bixin. Kandungan bixin yang diekstraksi memakai etil asetat menggunakan metode ekstraksi ultrasonic bath ini lebih tinggi, sesuai dengan hasil percobaan yang dilakukan oleh Cardarelli dkk. (2008).

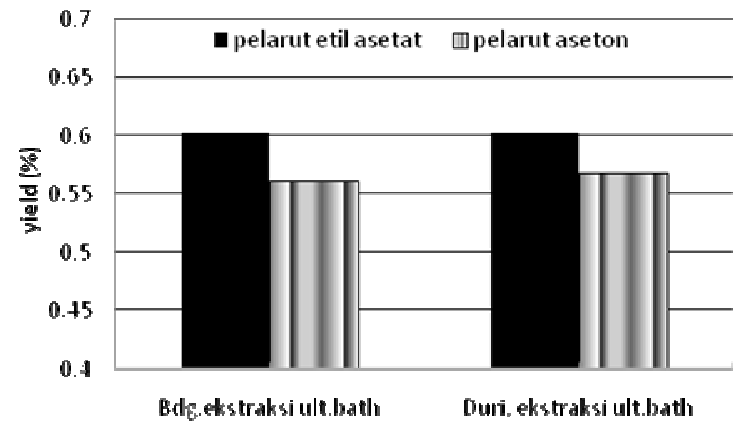

Gambar 3. Perbandingan perolehan bixin terhadap biji dari variasi pelarut dengan metode ekstraksi ultrasonic bath

Hasil percobaan ini menunjukkan pelarut yang memiliki indeks polaritas medium akan menghasilkan perolehan bixin lebih tinggi. Pelarut yang 
menghasilkan bixin tertinggi adalah etil asetat dengan indeks polaritas 4,4 .

Dengan metode Soxhlet memberikan hasil yang berbeda untuk dua jenis pelarut ini. Gambar 4 memperlihatkan perolehan bixin dengan memvariasikan pelarut pada metode ekstraksi Soxhlet. Perolehan bixin terhadap biji rata-rata untuk pelarut aseton adalah $0,460 \%$, sedangkan untuk pelarut etil asetat adalah $0,427 \%$. Hal ini dikarenakan suhu yang dipakai untuk metode Soxhlet adalah suhu titik didih larutan. Suhu titik didih etil asetat adalah $77^{\circ} \mathrm{C}$. Menurut Shuahama dkk. (2003) dan Massarani dkk. (1992), kandungan bixin menurun apabila terpapar pada suhu proses diatas $60^{\circ} \mathrm{C}$. Oleh karena itu, bixin yang menggunakan ekstraksi metode Soxhlet, walaupun menggunakan etil asetat yang memiliki nilai indeks polaritas medium, akan memiliki kandungan rendah akibat pemanasan yang menyebabkan degradasi warna.

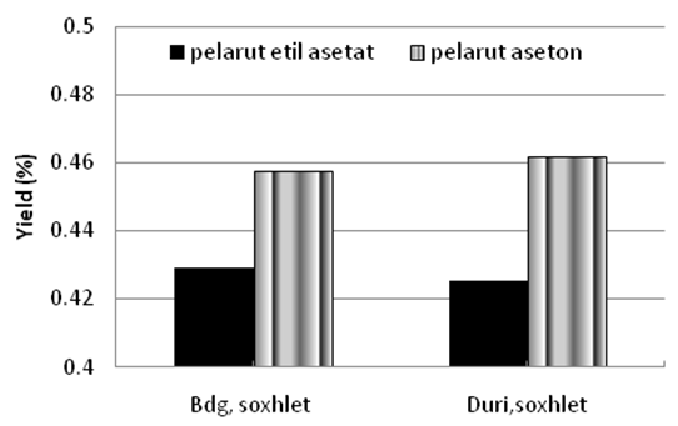

Gambar 4. Perbandingan perolehan bixin terhadap biji dari variasi pelarut dengan ekstraksi soxhlet

\section{Perolehan Bixin dari Variasi Sumber Biji Kesumba (Bixa orellana)}

Biji kasumba/galinggem yang dipakai dalam penelitian ini berasal dari dua tempat berbeda di Indonesia. Tempat pertama adalah Bandung Timur, Jawa Barat dan tempat kedua adalah Duri, Riau. Gambar 5 menunjukkan hasil penelitian perbandingan yield (perolehan) bixin terhadap biji dari sumber yang berbeda dengan berbagai metode-metode ekstraksi.

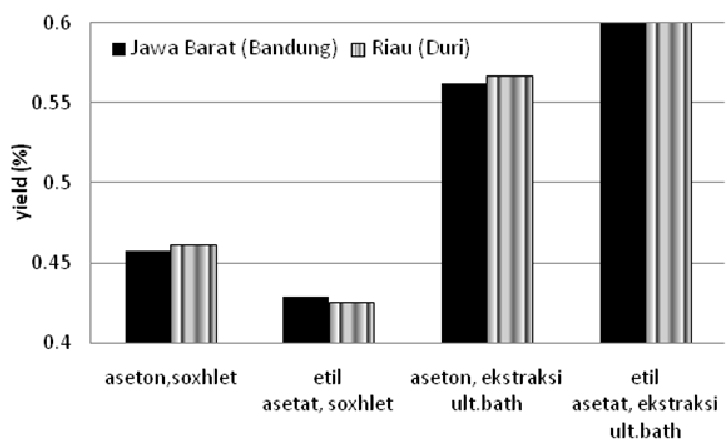

Gambar 5. Perbandingan perolehan bixin terhadap biji dari sumber yang berbeda
Hasil penelitian menunjukkan biji yang berasal dari 2 tempat berbeda, ketika diekstraksi tidak memberikan perbedaan yang signifikan terhadap hasil bixin dari kedua asal tempat.

\section{Pengaruh Suhu terhadap Perolehan untuk Metode Ekstraksi Ultrasonic Bath}

Setelah diperoleh yield bixin yang lebih tinggi dalam percobaan di atas maka percobaan lanjutan dilakukan dengan memvariasikan suhu ekstraksi pada rentang $30 \mathrm{oC}$ sampai $50 \mathrm{oC}$ dengan metode ultrasonic bath dan pelarut etil asetat. Percobaan dilakukan selama 90 menit. Gambar 6 menunjukkan hasil perbandingan perolehan Bixin (terhadap biji) sepanjang waktu untuk variasi suhu esktraksi. Pada 15 menit awal pertama, terlihat bahwa perolehan yang didapat semakin meningkat. Hal ini terus terjadi sampai 60 menit pada ketiga variasi suhu. Pada menit ke 60, konsentrasi bixin yang terekstrak mulai konstan. Selanjutnya sampai setelah 30 menit, konsentrasi terus menerus konstan.

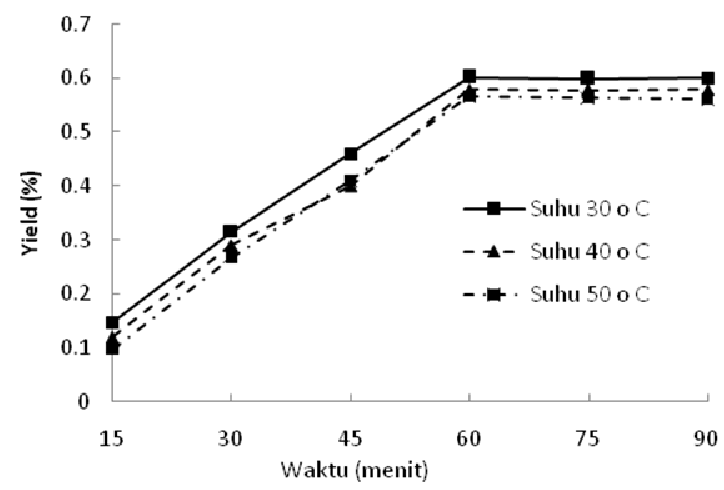

Gambar 6. Pengaruh suhu terhadap perolehan Bixin (dasar biji) untuk metode ultrasonic bath

Untuk variasi suhu, keadaan proses yang beroperasi pada suhu $30^{\circ} \mathrm{C}$ menunjukkan perolehan bixin yang paling tinggi, pada menit ke 60 , perolehan bixin terhadap biji mencapai $0,602 \%$. Perolehan yang terendah adalah suhu proses pada $50^{\circ} \mathrm{C}$ yaitu pada $0,566 \%$.

Massarani dkk. (1992) melakukan penelitian menggunakan spouted bed extractor dan menunjukkan trend/ perilaku yang sama dengan penelitian ini. Dimana kandungan bixin setelah $30^{\circ} \mathrm{C}$ menunjukkan penurunan. Hal ini dapat dijelaskan bahwa bixin yang terkena panas akan mengalami degradasi warna. Degradasi warna inilah yang membuat kualitas bixin menurun.

Dari hasil perolehan bixin $0,602 \%$ (w) maka dapat dibandingkan dengan perkiraan oleh Francis (2010) untuk biji kesumba berbentuk oval diperkirakan mengandung pigmen sejumlah 1,5\%-2\%, sedangkan untuk biji berbentuk konikal 3-3,5\%. Biji kesumba (Bixa orellana) dari Indonesia mempunyai bentuk oval dan sedikit berbentuk konikal, sehingga 
$0,602 \%$ ini masih cukup rendah dibandingkan kedua biji tersebut, walapun sekitar $50 \%$ dari kandungan biji kasumba oval.

\section{KESIMPULAN}

Dari hasil penelitian dalam skala bench ini dapat ditarik beberapa kesimpulan bahwa untuk ekstraksi menggunakan metode ultrasonic suhu kamar, yield (perolehan) bixin menggunakan pelarut etil asetat lebih tinggi, rata-rata sebesar 6,023 mg bixin/gram biji bixin, dibandingkan menggunakan aseton, rata-rata sebesar 5,65 $\mathrm{mg}$ bixin/gram biji. Percobaan yang dilakukan dengan metode Soxhlet memberikan hasil yang lebih rendah untuk dua jenis pelarut ini dibandingkan dengan metode ultrasonic. Nilai perolehan bixin rata-rata untuk pelarut aseton adalah 4,596 mg bixin/gram biji, sedangkan pelarut etil asetat adalah 4,28 $\mathrm{mg}$ bixin/gram biji.

Biji kesumba yang berasal dari dua tempat berbeda, dari Riau (Duri) dan Jawa Barat (Bandung), ketika diekstraksi tidak memberikan perolehan bixin yang berbeda dan perolehan hampir sama untuk masing-masing metode-metode ekstraksi. Untuk ekstraksi ultrasonic bath dengan pelarut etil asetat dengan variasi suhu $30^{\circ} \mathrm{C}, 40^{\circ} \mathrm{C}, 50^{\circ} \mathrm{C}$, maka proses beroperasi pada suhu $30^{\circ} \mathrm{C}$ menunjukkan perolehan bixin yang paling tinggi, mencapai $0,602 \%$ dibandingkan $0,566 \%$ pada $50^{\circ} \mathrm{C}$.

\section{UCAPAN TERIMA KASIH}

Ucapan terima kasih ditujukan kepada Bapak Komari di Program Studi Teknik Kimia FTI ITB atas bantuannya selama penelitian ini.

\section{Daftar Pustaka}

Amaya, D.B.R. and Kimura, M., (2004), Harvestplus Handbook for Carotenoid Analysis, HarvestPlus, Washington, DC.

Cardarelli, C.R., Bennasi, M.T., and Adriana Z., (2008), Characterization of Different Annatto Exctracts based on Antioxidant and Colour Properties, Food Science and Technology, 41, pp. 1689-1693.

FAO/WHO, (2006), FAO JECFA Monographs: Compendium of Food Additive Specifications, $67^{\text {th }}$ meeting.

Francis, J.K., (2010), Bixa orellana: Bixaceae, www.fs.fed.us/global/iitf/Bixa orellana.pdf.
Hendry, B.S., (1992), Natural Food Colours in Natural Food Colorants, Eds. Hendry, C.A.F and Houghton, J.D., Blackie \& Sons Ltd, Great Britain.

Heyne, K., (1950), Tanaman Berguna Indonesia, Badan Litbang Kehutanan, Jakarta.

Hyman, E. L., Chavez, R. J., and Skibiak, J., (1990), Reorienting Export Production to Benefit Rural Producers: Annatto Processing in Peru, Journal of Rural Studies, 1 (6), 85-101.

MacDougall, D.B., (2002), Colour in Food: Improving Quality, Woodhead Publishing Limited, Cambridge.

Massarani, G., Passos, M.L., and Barretos, D.W., (1992), Production of Annatto concentrates in spouted beds, The Canadian Journal of Chemical Engineering, 70, pp. 954-959.

Mercadante, A.Z., Steck, A., and Pfander, H., (1999), Three Minor Carotenoids from Annatto (Bixa orellana) seeds, Phytochemistry, 52, 135-139.

Ribeiro, J.A., Oliveira, D.T., Passos, M.L., and Barrozo, M.A.S., (2005), The Use of Nonlinearity Measures to Discriminate the Equilibrium Moisture Equations for Bixa orellana Seeds, Journal of Food Engineering, 1(66), pp. 63-68.

Rigaudy, H. and Klesney, S.P., (1979), Nomenclature of Organic Chemistry, Sections $A, B, C, D, E, F$, and $H$, Pergamon Press.

http://www.chem.qmul.ac.uk/iupac/carot/car8t13.html

Scotter, M., (2009), The Chemistry and analysis of annatto food colouring: a review, Food Additives and Contaminants, 8 (26), pp. 1123-1145.

Shuahama, I.K., Aguiar , M.L., Oliveira, W.P., and Freitas, L.A.P., (2003), Experimental production of annatto powders in spouted bed dryer, Journal of Food Engineering, 59, pp. 93-97.

Smith, J., (2006), Annatto Extracts: Chemical and Technical Assessment, Proc. $67^{\text {th }}$ JECFA, FAO. 